\title{
UNA APROXIMACIÓN A LA VIDA DE UNA MUJER DE LA ALTA SOCIEDAD DEL SIGLO XVII. FRANCISCA FERNÁNDEZ DE MERODIO
}

\author{
Mercedes Gómez Oreña* \\ Profesora de Historia en Enseñanza Secundaria
}

\begin{abstract}
RESUMEN
En este trabajo hemos plasmado la vida de Francisca Antonia Fernández de Merodio, una mujer de la alta sociedad del siglo XVII, esposa de un banquero y embajador, cuyo papel en su matrimonio se circunscribirá a ser madre y anfitriona doméstica para facilitar los intereses financieros y diplomáticos de su marido. La riqueza y opulencia desplegada en su mundo cotidiano contrastará con su religiosidad, a la que se asirá con mayor ímpetu cuando fallezcan prematuramente sus hijos en la más tierna infancia y cuando el único que sobreviva ingrese en la Compañía de Jesús, lo que marcará también su actitud ante la muerte.
\end{abstract}

PALABRAS CLAVES: mujer, siglo XVII, alta sociedad, mortalidad, religiosidad barroca

*mercedes.gomezorena@educa.madrid.org 


\title{
AN APPROACH TO THE LIFE OF A WOMAN OF THE HIGH SOCIETY OF THE 17TH CENTURY. FRANCISCA FERNÁNDEZ DE MERODIO
}

\author{
Mercedes Gómez Oreña* \\ Profesora de Historia en Enseñanza Secundaria
}

\begin{abstract}
In this paper we have captured the life of Francisca Antonia Fernández de Merodio, a seventeenth-century high society woman, wife of a banker and ambassador, whose role in her marriage will be limited to being a mother and domestic hostess to facilitate financial interests and diplomats of her husband. The wealth and opulence displayed in their daily world will contrast with their religiosity, to which they will cling more strongly when their children die prematurely in the earliest childhood and when the only one who survives enters the Company of Jesus, which will also mark their attitude towards death.
\end{abstract}

KEYWORDS: woman, 17th century, high society, mortality, baroque religiosity 


\section{INTRODUCCIÓN}

Las investigaciones sobre las mujeres de la Edad Moderna en las últimas décadas han suscitado un gran interés por parte de la historiografía. Contribuir al conocimiento del mundo femenino es el objetivo planteado en este trabajo, para ello nos adentraremos en la vida de una mujer de la alta sociedad del siglo XVII, Francisca Antonia Fernández de Merodio. Este estudio, junto a otros de igual naturaleza dentro de la historia social, servirá para que su contexto cotidiano sea reconocido más allá de la esfera biográfica de aquellas mujeres que han destacado, en mayor o menor medida, en el ámbito político, religioso o literario. En este caso concreto nuestra protagonista es ajena a cualquiera de estos, es por ello que nos hemos centrado más en cuestiones tratadas desde otros ámbitos como la antropología y la historia cultural que abordan el tema teniendo presente sus particularidades desde una perspectiva de género. De hecho, es destacable el papel diferenciador de los roles que establece la sociedad para el hombre y la mujer, que en la época que nos ocupa tenían un profundo carácter de supeditación de la segunda respecto al primero. Asimismo, se ha estudiado la disparidad suscitada por el estatus social que ocupaban estas, dado que las que pertenecían a la nobleza y burguesía gozaban de una serie de ventajas que no tenían las del extracto más bajo y las campesinas, puesto que además del acceso a la educación disfrutaban de una calidad de vida muy superior, como han quedado reflejadas estas cuestiones planteadas en distintas investigaciones ${ }^{1}$.

La historia de este personaje estará caracterizada por una profunda espiritualidad y devoción, estando presentes a lo largo de toda su vida, limitando desde muy temprano este contexto religioso las libertades y pensamientos de su sexo. Aun así, su situación privilegiada le harían gozar del lujo y la opulencia desplegados en sus viviendas y en la vida cotidiana, derivados, en gran medida, de las actividades financieras y del estatus diplomático de su marido. No obstante, la pérdida de sus seres queridos, especialmente la de sus hijos en la más tierna infancia, marcará profundamente su existencia.

Plasmar en estas líneas la vida de Francisca Antonia ha sido posible gracias a la importante documentación obtenida en diferentes archivos

1. Véase M. Vigil (1986), E. M. a García Guerra (1990), M. ${ }^{a}$ I. Barbeito Carneito (1990), C. Segura Graíño (ed.) (1997), M. a V. López-Cordón (1999), P. Tenorio Gómez (2001), E. Hernández Sandoica (2004), I. Morant (dir.) (2005), P. Pezzi Cristóbal (2012), M. Ruiz Sastre (2018), C. Sanz Ayán (2019) y L. Oliván Santaliestra (2019). 
históricos, siendo el de Protocolos de Madrid el más prolífero al habernos proporcionado datos relevantes sobre sus bienes y familia. También, los archivos eclesiásticos de varias iglesias de Madrid nos han aportado sustanciales datos sobre ellos. Asimismo, las referencias de las actividades diplomáticas y mercantiles de su marido las hemos obtenido del Archivo Histórico Nacional, del General de Simancas y de la Biblioteca de la Real Academia de la Historia, donde se encuentra la correspondencia privada e inventario de sus bienes. El motivo de que exista un extraordinario volumen de documentos se debe a que el Colegio Jesuita de Alcalá de Henares sería el heredero de la fortuna del matrimonio. Esta institución conservaría papeles, libros contables y legajos como garantía de su posesión hasta la disolución de la Compañía de Jesús, que serían desperdigados en los archivos señalados anteriormente, así como en el Fondo Antiguo de la Universidad de Granada. En este lugar se depositó la carta del jesuita Gabriel de Bousemart a los padres provinciales de Toledo en la que relata la vida y virtudes del hijo de Francisca Antonia, eminente matemático, miembro fundador de la Real Academia de la Lengua y consultor del Santo Oficio. Estando sus obras localizadas en la Biblioteca Nacional y en la del Marqués de Valdecilla de la Universidad Complutense.

\section{LOS ORÍGENES FAMILIARES}

La familia paterna de Francisca Fernández de Merodio Valdés era oriunda de Antequera. Su abuelo, Miguel Fernández de Merodio, pertenecía a la burguesía de la ciudad, donde desempeñó los cargos de receptor de justicia y alcaide de la cárcel de la localidad. Contrajo matrimonio con Catalina Navarrete, con la que tuvo cinco hijos: Miguel, padre de la protagonista de nuestro estudio, Francisco, Manuel, María y Jerónima. El primogénito siguió la carrera judicial y desempeñó los empleos de abogado de los Reales Consejos, juez de la visita general de los alguaciles de la corte y ayudante fiscal del Consejo de Castilla. La actividad profesional del segundo la desconocemos, de él solo nos consta que estuvo casado con María de Mesa, con la que no tuvo descendencia. El tercero fue capitán de barco mercante, actividad que le permitió conocer a la tinerfeña Leonor de Betancur, con la que contrajo matrimonio, de cuya unión nacería Manuel. Por su parte, las dos féminas tomarían la senda religiosa en el Convento agustino de Santa Mónica de Antequera² ${ }^{2}$

2. Archivo Histórico de Protocolos de Madrid (AHPNM), Protocolo (P. ${ }^{\circ}$ 5694, fols. 1144-1149; P. ${ }^{\circ} 8715$, fols. 582-588, y P. ${ }^{\circ} 8712$, fols. 74-76. 
Los orígenes madrileños de la familia materna se remontan, al menos, hasta los bisabuelos Pedro de Alcacex o Alcacer y María de Valdés, que engendraron a María y Lope. La primera se casó con el agente de negocios Manuel de Pernia, con el que no tuvo sucesión. Lope, por el contario, tuvo a Francisca y María con su primera esposa, Francisca de San Vicente y Ancurica. Sin embargo, la temprana muerte de esta cuando las pequeñas tenían siete y cuatro años abocó al padre a contraer un nuevo enlace con otra madrileña, María de Castro, con la que no tuvo descendencia ${ }^{3}$.

Lope regentaba una botica en la calle de Santiago de Madrid, que posiblemente heredó de su abuelo materno, lo que explicaría que tomara el apellido de su progenitora en lugar del paterno que era lo acostumbrado. Cuando su hija Francisca tuvo edad para contraer matrimonio buscó en el gremio de boticarios al pretendiente, optando por el hijo de uno de ellos, Jerónimo de Villaizán 4 . Si bien, este no siguió el oficio de su padre, sino el de abogado de los Reales Consejos, el cual compaginaría con el de dramaturgo, con el que obtuvo una gran fama. De hecho, entre sus admiradores se encontraba el propio Felipe IV. El monarca, para asistir secretamente a sus representaciones, mandó construir un pasadizo desde la plazuela del Ángel al aposento real del Teatro de la Cruz. Cabe la posibilidad que este corredor partiera desde la propia vivienda del autor, pues habitaba en la citada plazuela en la casa que su esposa aportó al matrimonio como dote. La brillante carrera de Jerónimo de Villaizán le supuso el recelo de sus compañeros de pluma, quienes desaprobaban que compaginara la abogacía con la escritura, por lo que le injuriaban señalándole como hijo de un simple boticario. Su repentina muerte, acaecida en 1633, acabó con las críticas que sobre él esparcieron, lamentando solamente el deceso Lope de Vega ${ }^{5}$. Cuando se produjo el fallecimiento Francisca tenía tan solo veintitrés años, lo que forzó al padre a concertar un nuevo enlace unos meses más tarde. En esta ocasión el candidato sería otro abogado de los Reales Consejos, Miguel Fernández de Merodio. Después de la boda, celebrada el 24 de junio de 1634, los contrayentes se instalaron en la casa que la novia aportó como dote en ambos esponsales ${ }^{6}$. De este matrimonio nacieron seis hijos: Simón Francisco, María Micaela, Miguel, Martín, Sebastiana y Francisca Antonia, sobre la que versa

3. Archivo de la Parroquia de Santiago de Madrid (APSM), Libro de Bautismo n. ${ }^{\circ}$ 3, fol. 141 y 181; Libro de Defunciones n. ${ }^{\circ} 2$, fol. 65, y Libro de Matrimonios n. ${ }^{\circ} 2$.

4. AHPNM, P. ${ }^{\circ} 8713$, fols. 197-200r.

5. H. Urzáiz Tortajada (2002).

6. AHPNM, Biblioteca sig. 1430, Planimetría General de Madrid y Planos sig. 1431 y P. ${ }^{\circ} 8717$, fols. $690-809$. 
nuestra investigación ${ }^{7}$. La llegada al mundo de los hijos fue un acontecimiento muy dichoso para los progenitores, sin embargo, también sufrieron la pérdida de dos de ellos. El 15 de octubre de 1641, con tan solo dos años, se produjo el deceso de María Micaela. Este hecho se produjo apenas cinco meses después de haber nacido Miguel, quien fallecería en plena juventud, poco antes de cumplir diecinueve años ${ }^{8}$. Aunque la fecha exacta de su muerte la desconocemos, nos consta que se produjo entre finales de marzo y comienzos de abril de 1659. Durante su vida gozó de una pésima salud, pese a ello sus padres el 29 de abril de 1656 le dejaron ingresar como novicio en el Convento de Nuestra Señora de la Merced Calzada9 .

La primera defunción posiblemente constriñó a los progenitores a formalizar un mayorazgo, el cual establecieron con el único inmueble que poseían, que era el hogar que habitaban de la plazuela del Ángel. El 31 de diciembre de 1642 realizaron la escritura en la que establecieron como primer beneficiario al primogénito, al que seguiría el segundo, si el anterior fallecía sin herederos. Siguieron la línea hereditaria de padres a hijos, de preeminencia del mayor sobre el menor y del varón sobre la hembra, así sucesivamente hasta agotar la descendencia de parentesco en primer grado, que concluía en ese momento en el benjamín, Martín. Después de ellos accedían al vínculo María y Jerónima, las hermanas de Miguel Fernández de Merodio. Resulta paradójico que, pese a ser la vivienda un bien dotal de Francisca Valdés, pasase primero por la rama de su marido en lugar de establecer al familiar más directo de ella, su tía María de Valdés, quien será señalada en penúltimo lugar tras Manuel, el sobrino de Miguel Fernández de Merodio, y sus hijos legítimos. Por otro lado, es reseñable que las primeras eran monjas profesas en el Convento de Agustinas de Santa Mónica de Antequera, como ya hemos señalado, lo cual contradecía una de las disposiciones de la propia escritura en la que se remarca que la casa no se podía vender, donar o pasar a personas de orden sacro, con excepción de que tuvieran descendencia legítima o solicitasen dispensa papal para salir del estado religioso y casarse. Por último, ante la desaparición de los anteriores, el legítimo heredero del mayorazgo sería el Hospital General de la ciudad de Antequera ${ }^{10}$.

7. Archivo Diocesano de Madrid (ADM), Libro de Bautismo de la Parroquia de Santa Cruz, sig. SC8. fols. 37v, 103r, 204r; SC9, fols. 19, 135v y 327.

8. ADM, Parroquia de Santa Cruz, Libro de Defunciones SC63 (1638-1648), fol. 254.

9. AHPNM, P. ${ }^{\circ} 8717$, fols. 690-809.

10. AHPNM, P. ${ }^{\circ}$ 5694, fols. 1144-1149r. 


\section{GENEALOGÍA DE FRANCISCA ANTONIA FERNÁNDEZ DE MERODIO}

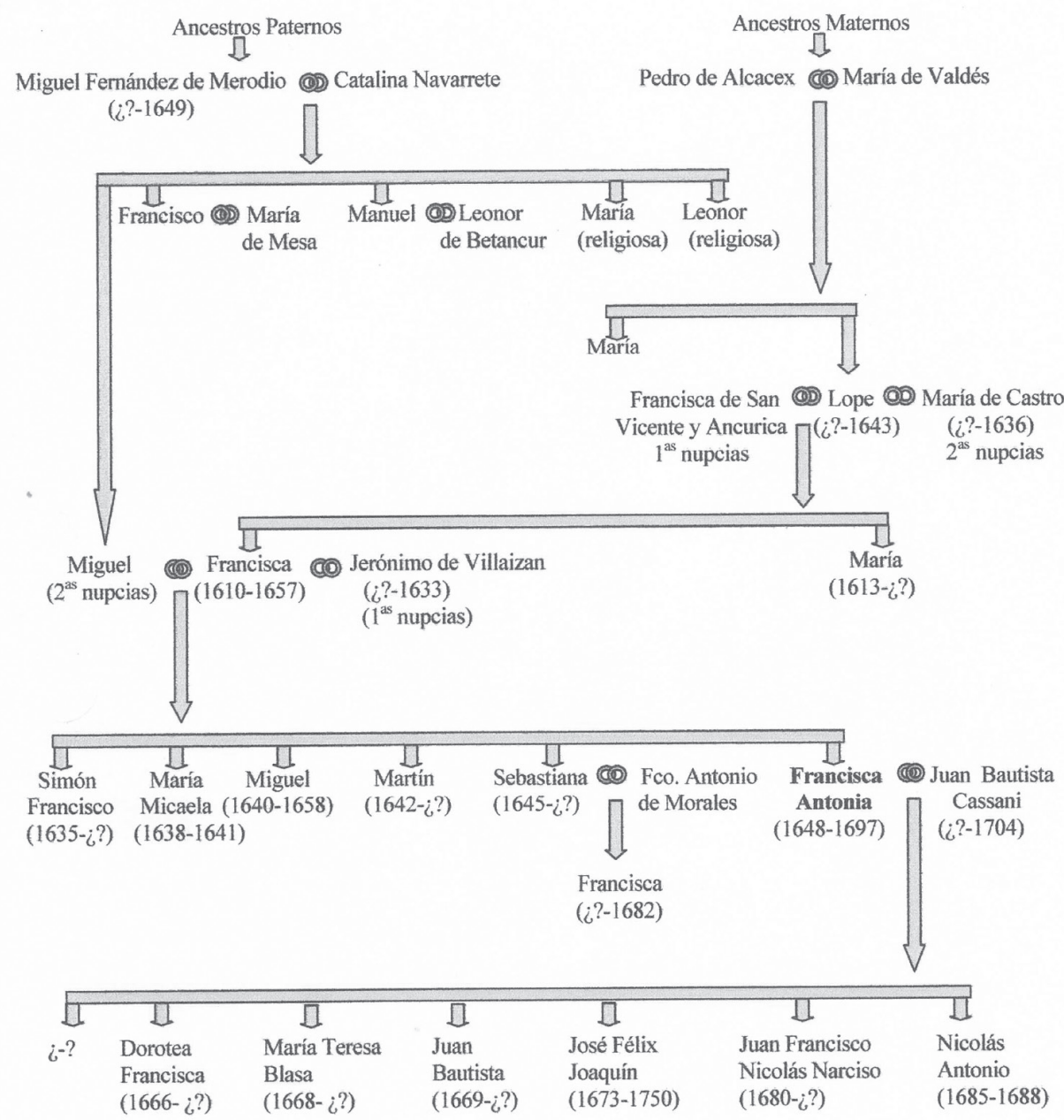

Esta escritura catorce años más tarde será sustituida por otra como consecuencia de los cambios que se produjeron en el seno familiar. En primer lugar, el hijo mayor, Simón, que estudió derecho como su padre, optó por la carrera religiosa dentro del clero secular, por lo que no podía heredar el mayorazgo. El siguiente en la sucesión, Miguel, tampoco podía hacerlo por haber optado asimismo por la vida espiritual, aunque dentro del seno regular. Por otra parte, los abuelos habían fallecido: Lope de Valdés en agosto de 1643, lo que incrementó considerablemente los bienes, pues 
el difunto contaba con un importante patrimonio, y Miguel Fernández de Merodio, que lo hizo en enero de 1649, vinculando el oficio de alcaide de la cárcel de Antequera a sus nietos Miguel y Martín. Además, los progenitores adquirieron otras dos casas en la calle de Silva y una tercera en la calle del Olivo. El documento sería firmado el 9 de febrero de 1656, pero en este caso no se siguió la línea sucesoria ni la prelación del varón sobre la hembra ${ }^{11}$. Será llamada en primer lugar la pequeña de todos los hermanos, Francisca Antonia, después pasaría a sus vástagos, en caso de no existir la heredera sería Sebastiana, quien si tampoco tuviera descendientes se transferiría a Martín. En este documento también sitúan a la familia de Miguel por delante, imponiendo a su sobrino Manuel tras los anteriores, para concluir con su hijo mayor, Simón, y tras este el Hospital General de Antequera ${ }^{12}$.

Las razones que llevaron al matrimonio a establecer un mayorazgo de feminidad, para el que se precisaba permiso real, frente al de masculinidad, que era el establecido por las leyes ordinarias, quizás vino determinado por la tendencia de los hijos varones hacia la vida religiosa. No obstante, no hemos podido concretar por qué eligieron a la pequeña en menoscabo de la mayor, precisamente cuando a esta última le asignaron la legítima de su hermano Miguel antes de profesar como religioso. Fuera como fuere, lo cierto es que la dote que aportarían ambas al matrimonio facilitaría un enlace acomodado.

\section{EL DECESO MATERNO Y LA FRAGMENTACIÓN DEL HOGAR}

Los datos estudiados nos hacen pensar que la primera infancia de Francisca Antonia transcurrió en un entorno doméstico feliz y dichoso, dado que la disponibilidad económica de la familia permitía una vida de opulencia y bienestar, como ha quedado reflejado en el inventario post-mortem realizado tras la muerte de su padre ${ }^{13}$. Sin embargo, esta situación cambió bruscamente cuando la madre cayó enferma. Su salud se fue agravando hasta que al amanecer del sábado 30 de junio de 1657 falleció. Al día siguiente sería enterrada en el monasterio en el que se hallaba su hijo Miguel ${ }^{14}$. La aflicción por la pérdida de su esposa

11. AHPNM, P. ${ }^{\circ} 8712$, fols. $74-75 \mathrm{v}$.

12. R. Camacho Martínez (1980), pp. 63-74. En 1712 el citado convento heredó el mayorazgo. Archivo Histórico Nacional (AHN), leg. 611, n. ${ }^{\circ} 4$.

13. AHPNM, P. ${ }^{\circ} 8717$, pp. 289-231

14. ADM, Parroquia de la Santa Cruz, Libro de defunciones SC64, fol. 258v. 
alentó a su marido a ingresar como hermano en la misma institución religiosa, lo que afectaba directamente a sus vástagos, especialmente a las pequeñas, cuya vida daría un giro drástico, pues a la pérdida materna se sumaba la privación del consuelo y cariño de su progenitor, que desaparecería también de sus vidas. Esta decisión obligaba al patriarca a dejarlas asistidas bajo la tutela de algún familiar. En Madrid contaba con los parientes de su mujer, con los que existía una óptima relación, como lo prueba el hecho de que fueran tenidos en cuenta en su testamento ${ }^{15}$. No obstante, María, la hermana del padre, nada más conocer la noticia del fallecimiento de su cuñada, insistió para que las enviara a su convento donde quedarían bajo su custodia, porque así viviría tranquilo y sosegado, ya que la ciudad "está hoy en tal estado, y más peligro tienen las hembras que los jóvenes". Las dudas sobre esta decisión se desvanecieron cuando María le expuso que con un simple permiso del provincial podrían acceder como pupilas para criarse allí, como así lo había realizado Diego de Centurión con sus hijas, que las tuvo allí seis años y pasado este tiempo las sacó sin problemas ${ }^{16}$.

Esta seguridad paterna conllevaba un cambio sustancial en la vida de Sebastiana y Francisca Antonia, que contaban con nueve y once años de edad, pues finalmente quedaron enclaustradas junto a sus tías religiosas, a las que ni siquiera conocían. Además, se hallaban muy lejos de su hogar, a lo que había que sumar el largo viaje hasta el nuevo destino, que, al menos, lo realizaron en compañía de su padre. Durante el breve tiempo que estuvo este en Antequera se ocupó de gestionar con su hermana María todas las cuestiones referentes a la crianza y sustento de las pequeñas. De las cuentas entregadas por las religiosas ante el escribano antequerano Antonio Fernández de Morales se desprende que su progenitor no deseaba que se escatimara en nada. Le preocupaba especialmente su descanso y alimentación, por ese motivo lo primero que adquirió María para ellas fue una cama alta con cordeles, dos colchones bien tupidos de lana y un surtido importante de provisiones. Con el tiempo también renovarían el vestuario de luto que habían llevado desde Madrid ${ }^{17}$.

15. AHPNM, $\mathrm{P}^{\circ}{ }^{8713}$, fol. $197-200$ r.

16. AHPNM, P. $^{\circ} 8717$, fols. 505-507.

17. AHPNM, P. ${ }^{\circ} 8717$, fols. 540-541. En abastecimiento en un primer momento fue de un cerdo entero, tres patas para salchichas, un cabrito, dos fanegas de trigo, una de aceitunas, dos mil nueces, tres libras y cuarto de azúcar y una arroba de pasas. Para el vestuario adquirieron varios metros de tela negra de lanilla, lienzo, tafetán y sedas, así como cuatro pares de zapatos, dos de palillo y dos planos. 
A pesar del esfuerzo que realizaron las religiosas para que las dos pequeñas estuvieran lo más confortablemente posible en su retiro, adaptarse a la vida conventual supondría para ellas una situación difícil de sobrellevar, pues el pasar de las horas y los días estaban estructurados en torno a los ciclos litúrgicos y a los rezos canónicos, los cuales se iniciaban muy temprano y concluían muy tarde. Aun no siendo su ingreso de iniciación en la vida espiritual, las dos hermanas estuvieron bajo la custodia de la maestra de novicias. La función de esta religiosa era instruir a las neófitas bajo su cargo en todo lo concerniente a la vida monástica, siendo su tutela y guía para cuestiones divinas, como hacer oración y mortificarse. Sin embargo, iniciarlas en la lectura y escritura no fue el objetivo de su maestra, pues la instrucción estaba reservada a los hombres, de hecho, muy pocas mujeres tenían acceso a ella, entre otros motivos porque los moralistas de la época lo desaconsejan. En todo caso, aceptaban que las de la alta sociedad lo hicieran para leer los libros devocionales ${ }^{18}$. Lo cierto es que Francisca Antonia después de haber pasado dos años en dicha institución no sabía escribir, teniendo que firmar por ella otra persona cuando precisó hacerlo. Otras ocupaciones como el bordado y la costura llenarían las jornadas de la tarde, estando las de la mañana más en concordancia con el óptimo funcionamiento del claustro: limpieza, servicio de cocina y ayuda en el huerto. De estos desempeños matutinos las dos hermanas estaban exentas de realizarlos, pues nos consta que la antequerana Lorenzana de Olivares era la encargada de lavar sus prendas. Todas estas actividades servían a las novicias para adaptarse a la vida conventual y en el caso de las dos hermanas para ser buenas esposas y madres ${ }^{19}$.

El tiempo de reclusión en el entorno monástico estaba determinado que fuera para cinco años, pero después del segundo ocurrieron dos tristes acontecimientos, la defunción de su hermano Miguel y poco después la del padre, que se produjo en agosto de $1659^{20}$. Esta última cambiaría la situación de Sebastiana y Francisca Antonia, que serían separadas a los tres meses del deceso paterno, pues el escribano de Antequera que se ocupaba de gestionar las cuestiones concernientes al mantenimiento de las pequeñas, al ser conocedor de la importante fortuna que heredaban, casó a Sebastiana,

18. Sobre la instrucción de las mujeres véase P. Martínez de Oporto (2019).

19. Para las actividades cotidianas de un convento véase M. C. Toquica Clavijo (2001).

20. AHPNM, P. ${ }^{\circ} 8717$, fols. 535-536. 
que apenas tenía trece años, con su hijo Francisco Antonio ${ }^{21}$. Sin embargo, cabe la posibilidad de que desconociera que la titularidad del mayorazgo recaía en la pequeña, pues solo se explica que casara a su vástago con la mayor por la seguridad de no perder la hacienda que heredaba esta, pues el enlace con Francisca Antonia no se hubiera podido realizar en ese momento por su minoría de edad, tenía once años y hasta los doce las autoridades no permitían que se formalizara. Por otro lado, la concertación de este matrimonio le permitía concurrir al reparto de los bienes del difunto, no solo en defensa de los intereses de su nuera, sino también de los de su hermana, para la que se constituyó como su curador, y de las tías religiosas, quienes asimismo confiaron en él para que percibiera en su nombre la adjudicación de 100 ducados de renta anuales que les legó su hermano ${ }^{22}$.

La documentación consultada nos revela que la permanencia de Francisca Antonia en el convento sin Sebastiana resultó muy dolorosa para ella. Sus tías intentaron aliviarla con algún que otro regalo, pero no pudieron suplir la ausencia de esta última, para la que suponemos debió de ser también difícil la separación. Esta sería mayor cuando su hermano Simón asumió la tutoría de su hermana, a la que trasladaría a Madrid para concertar un ventajoso matrimonio. La importante fortuna de la joven hacía previsible un rápido enlace, por lo que en lugar de permanecer en el hogar paterno prefirió ingresarla en el convento de monjas franciscanas de la Visitación de Nuestra Señora ${ }^{23}$.

\section{MATRIMONIO, DESCENDENCIA Y HOGAR}

Simón concertó la boda de Francisca Antonia con un financiero, Juan Bautista Cassani Vivaldo. Sus orígenes se situaban en Taggia, ciudad genovesa, donde nació en torno a finales de los años veinte y comienzo de los

21. AHPNM, P. ${ }^{\circ} 8717$, fols. 339-339r, 508, 535-536 y 582-588, y P. ${ }^{\circ} 8715$, fols. 582-588. El escribano tenía conocimiento de la herencia por la estrecha relación profesional que mantuvo con el padre, quien delegó en él la gestión de las propiedades de Antequera: las rentas de la casa de la calle Galdopal, que había heredado de su hermano Francisco, y las del oficio de alcaide de la cárcel de dicha ciudad que pertenecía a sus hijos Miguel y Martín. Por otro lado, el escribano conocía el patrimonio que poseían las pequeñas en Madrid desde que Miguel Fernández acudió al entierro de su progenitor, ya que en ese tiempo realizó un testamento en su notaria indicando que por ser albacea de su suegro había cobrado las rentas de las casas y otros bienes que le pertenecieron a este último.

22. AHPNM, P. ${ }^{\circ} 8715$, fols. 582-588.

23. AHPNM, P. ${ }^{\circ} 10289$, fols. $918-922$ r. 
treinta del siglo XVII. Los padres, Juan María Cassani y Benedicta Vivaldo, formaban parte de la élite comercial de la república ligur. Del primero apenas tenemos referencias, nos inclinamos a pensar que era un activo comerciante, ya que su mujer pertenecía a la estirpe de los Vivaldo, importantes hombres de negocios que operaban a escala internacional y miembros activos de la política de su nación ${ }^{24}$. Estos últimos estaban instalados en España desde finales del siglo XIII, cuando los hermanos Bonavía, Pagano y Jácome Vivaldo se establecieron en Sevilla ${ }^{25}$. Con posterioridad siempre habrá varios miembros situados en diferentes ciudades de la Península Ibérica, la ya mencionada Sevilla, el Puerto de Santa María, Medina del Campo, Madrid y Toledo. En compañía de sus paisanos los Grimaldo se constituyeron en los segundos banqueros más importantes encargados de expedir a Roma el numerario de los frutos eclesiales que la colectoría de España arrendaba ${ }^{26}$. La infraestructura montada en torno a este negocio facilitó que la Cámara Apostólica les confiara la tesorería de los reinos hispánicos. Asimismo, el Consejo de Italia utilizó sus servicios para transferir dinero de los territorios de Milán, Nápoles y Sicilia, al igual que lo hicieron miembros de la nobleza que tenían beneficios en esos dominios. Los intereses obtenidos les permitieron diversificar los negocios, constituyéndose como asentistas reales, lo que a su vez les facultó para acceder a la venta de títulos nobiliarios y mercedes reales. También concedieron préstamos a particulares e importaron y exportaron lanas, diamantes y joyas.

El volumen monetario que generaron todas estas actividades y las relaciones clientelares entre los miembros más importantes de la política española le permitió a Juan Bautista Cassani ser elegido como residente embajador de la República de los Cantones Católicos en la corte de la Monarquía Hispánica. Antes de acceder a ella había tras de sí un largo recorrido que comenzó siendo aún muy pequeño cuando sus padres y hermanos Domingo María, Marcos, Francisca y Ana Teresa se trasladaron a Roma. Allí los jóvenes realizaron sus estudios en el colegio jesuita de esta ciudad. Concluidos estos, y siguiendo una práctica habitual en las compañías genovesas, ingresaban en la firma familiar para instruirse en el entramado mercantil de la misma. Dentro del ciclo formativo se contemplaba el traslado en un momento determinado a una filial exterior. La ocasión para Juan Bautista Cassani se produjo por el fallecimiento en Madrid de

24. J. F. F. de Rivarola y Pineda (1729), 419.

25. J. Jiménez López de Eguileta (2018), 133-147.

26. J. M. Carretero Zamora (2013), 79-103. 
varios familiares en un corto periodo de tiempo. A cargo de la misma se hallaba un primo de él, Juan Francisco Pascua, quien le iniciaría durante dos años en el conglomerado financiero de la corte. En 1658 este último tuvo que desplazarse a Nápoles para gestionar los negocios que allí poseía, lo que situó al primero como administrador único de la casa. Este acontecimiento determinaba que la estancia transitoria de Juan Bautista Cassani se convirtiera en permanente, de ahí que se planteara formar una familia. Para ello precisaba conocer a las candidatas disponibles, las cuales podrían proporcionarle un estatus de nobleza o una importante fortuna. En ambos casos debía quedar probado su honor e inmaculado cuerpo ${ }^{27}$.

Cuando a Francisca Antonia le quedaban seis meses para cumplir quince años Simón concertó su matrimonio. La elección no debió ser fácil al tener que conjugar dinero y posición social en una misma persona. También tendría presente la edad, ni muy joven, ni excesivamente mayor, pues aunque Juan Bautista Cassani doblaba la edad de la candidata era todavía una persona en pleno apogeo vital. Pese a no conocer cuando se produjeron las primeras conversaciones entre Simón y Juan Bautista Cassani, sabemos que el acuerdo contractual entre ellos se realizó el 24 de enero de 1663. Previamente Francisca Antonia le había entregado un poder notarial a su hermano para que acordara las capitulaciones matrimoniales con el susodicho. Es reseñable que este documento fuera firmado por la novia, lo cual nos hace pensar que en el retiro del convento madrileño pudo haber aprendido los rudimentos de la escritura o, simplemente, la enseñaron a estampar su firma.

En las cláusulas se dispuso que la pareja se velara y desposara legítimamente, estableciendo que si alguno de los dos no cumplía lo pactado abonaría 2.000 ducados al otro, asegurando de esta forma el enlace. Su incumplimiento podría acarrear problemas judiciales, pues las leyes relativas al dolo y engaño, establecidas en el corpus legislativo de la Corona de Castilla desde 1348, establecían que aquello que se ajustaba y contrataba en caso de no cumplirse se pagaría la mitad del justo precio. Aunque las rupturas de noviazgo fueron muy frecuentes pocas acabaron en los tribunales, dado que se solía llegar a un acuerdo previo. De hecho, Juan Bautista Cassani se encargó de abonar años más tarde cierta cantidad a una joven a la que su hermano Marcos dio palabra de matrimonio, de la que después se retrac-

27. Sobre la actividad mercantil y diplomática de Juan Bautista Cassani véase M. Gómez OREÑa (2017) y (2018a). 
tó $^{28}$. En las capitulaciones también se registró la dote que llevaría la novia, cuyo valor ascendía a casi 400.000 reales de vellón. Esta estaba compuesta por varias casas, censos, algunos adeudos que quedaron pendientes tras el fallecimiento de su padre, el importe que le tocó de la venta en almoneda de los bienes de sus progenitores, más un aderezo de diamantes y perlas, ocho almohadas de estrado de terciopelo carmesí, una silla de manos, unos escritorios de cachas de ébano con pies de caoba y "otras cosas que están en fe". Por su parte, el novio ofreció llevar al matrimonio los bienes y efectos que en ese momento poseía. Asimismo, prometió en arras y donación a Francisca Antonia para aumento de su dote "por su nueva calidad, y virtud, y honor de su virginidad y demás buenas partes que en ella concurren" 45.000 reales de vellón, que señaló representaban la décima parte de los bienes que poseía en ese momento. Esta cantidad era muy importante, ya que es similar a la que algunos miembros de la nobleza entregaban a sus esposas, caso del marqués de Peñafiel, entre otros ${ }^{29}$. Dos años después de haberse celebrado el enlace se liquidaron todas las cuestiones concernientes a la dote y curaduría. Simón traspasó a Juan Bautista las cantidades que había percibido de las rentas de las casas cuando fue tutor de su hermana, más 888 reales de vellón que había ordenado su padre se dieran a su hija Francisca Antonia cuando se casara, los cuales estuvieron depositados en el escribano Antonio Fernández de Morales ${ }^{30}$.

Estipuladas las citadas capitulaciones los desposorios se celebraron el 11 de abril de 1663 en el convento donde se hallaba Francisca Antonia. Atendiendo a que Juan Bautista era tesorero de la Cámara Apostólica, dependiente de la Nunciatura de Madrid, la ceremonia fue oficiada por su auditor, Jacobo de Santuccio. Los testigos fueron Sebastián Peralta, secretario del Consejo de Castilla, Lorenzo Matheu, alcalde de la casa y corte e íntimo amigo del novio, y Simón ${ }^{31}$. Después de la ceremonia la pareja se trasladó a la residencia del novio, un edificio que pertenecía a los herederos de su tío Pedro María Vivaldo, a los que se lo comprará en 1667 para reconstruirlo por completo y adaptarlo a su gusto ${ }^{32}$. Este se ubicaba

28. AHPNM, P. ${ }^{0} 11447$, fols. $823-824 v$. Sobre las promesas incumplidas y rupturas de noviazgo véase M. Ruiz SAStre (2018).

29. M. Á. López Millán (2014).

30. AHPNM, P. ${ }^{\circ} 8357$, sin foliar, y P. ${ }^{\circ} 11447$, fols. 355-356.

31. APSM, Libro de Matrimonios n. ${ }^{\circ}$ 4, fol. 84.

32. AHPNM, P. ${ }^{\circ} 5702$, fols. 442-444v; P. ${ }^{\circ} 7925$, fols. 542-546r. AHN, Delegación de Hacienda de Madrid, Libro 8, fols. 255-257v. 
en la calle del Lobo ${ }^{33}$, actual Echegaray, en el Barrio de las Letras, donde residían las personalidades del mundo del teatro y la colonia de italianos de la corte, en la que disponían de su propio hospital e iglesia, la de San Pedro y San Pablo de los Italianos, del que Juan Bautista llegó a ser gobernador. El citado barrio pertenecía a la parroquia de San Sebastián, donde casi un año después de haberse celebrado el matrimonio entregaron la certificación de la unión ${ }^{34}$.

La boda libró a Francisca Antonia de su retiro conventual, cambiando por completo su estilo de vida. El nacimiento de los hijos será un motivo de alegría para la pareja, creemos que el primer parto se produjo al año siguiente de celebrado el enlace, sin embargo, no hemos podido localizar el registro bautismal para poderlo confirmar. La siguiente en venir al mundo fue Dorotea Francisca María, que lo hizo el 8 de febrero de 1666, fue bautizada y apadrinada por el presbítero Juan Bautista Ruxero, mayordomo de la casa. También por esta época su hermana Sebastiana, que había enviudado y tenía una niña de muy corta edad, regresó a Madrid para estar juntas y criar a sus respectivas hijas, a las que habían impuesto el nombre de la abuela. Para mayor comodidad Sebastiana alquiló una casa apenas a unos metros de la de su hermana, en la misma calle del Lobo, esquina con la del Prado 35 .

La vida de Francisca Antonia se había transformado drásticamente tras su matrimonio, pero cambiaría aún más cuando su marido fue nombrado embajador de la República de los Cantones Católicos. El estatus de diplomático conllevaba un viraje en los quehaceres cotidianos, pues estos se desarrollaban con una mayor magnificencia. Los primeros cambios se realizaron en la casa, en el solar ocupado por esta construyó dos viviendas con los mismos elementos habitacionales: cueva, sótano, tres plantas de calle y desván. El matrimonio ocuparía una de ellas, a la que se accedía por grandes puertas carreteras que daban paso al zaguán, el cual estaba losado con piedra berroqueña. Desde este elemento distribuidor se accedía al escritorio de comercio, a la cocina, a otras estancias y a dos patios. El más pequeño servía para el acomodo de las mulas y para guardar los ricos carruajes que poseían - dos estufas, dos forlones, un carrocín y varias sillas de mano-, mientras que el más grande lo utilizaban para el deleite de la

33. AHPNM, Prot. 8354, fols. 1248-1252r. L. M. ApArisi LAPORTA (2001).

34. Archivo de la Parroquia de San Sebastián de Madrid (APSSM), Matrimonio, Libro 1660, año 1664.

35. APSSM, Libro de Índices, n. ${ }^{\circ} 3$. 
familia, de ahí que para mayor comodidad fuera pavimentado con la misma piedra berroqueña y decorado con una columna de casi cinco metros ${ }^{36}$.

La elegancia de la escalera que daba acceso al piso superior se incrementaba con los grandes espejos de marcos labrados que colgaban de las paredes de los descansillos. En esta planta noble se hallaba la habitación de respeto en la que Francisca Antonia recibía a sus visitas. Las más allegadas ocupaban la parte del estrado que estaba cubierto por una rica alfombra de Mesina y cojines de Damasco esparcidos por el suelo. También había algunos bufetes donde se colocaban los dulces y otras golosinas para agasajar a las damas más importantes de la corte, pues su nueva condición de esposa de embajador exigía realizar recepciones para ellas cuando la ocasión lo requería. De hecho, ciertos asuntos de su marido se lograron gracias a su valía como anfitriona. En la parte exterior de esta plataforma, en exquisitas vitrinas y escaparates se exhibían imágenes y objetos de gran valor, además de un espléndido mobiliario de madera con incrustaciones de plata, nácar y marfil. Incluso el lujo de esta y del resto de las habitaciones se haría visible a través de las grandes obras pictóricas y tapices.

En este mismo nivel de la casa se situaban los dormitorios con sus respectivas alcobas, donde las ricas camas con dosel y cortinas de Damasco, junto a los biombos, armarios, baúles y arcas llenaban las estancias. En otra pieza de esta planta se ubicaba el oratorio que estaba ricamente decorado con una bella mesa de altar y muebles donde guardar los utensilios litúrgicos. Al lado de él la biblioteca, en cuyos estantes de escalerillas se hallaba una importante colección de más de 200 libros de diferente temática, ya que su esposo e hijo nos consta fueron ávidos lectores. La distribución de este piso se completaba con un largo corredor que daba al patio principal y las escaleras de acceso al superior, donde se ubicaba una segunda cocina y las habitaciones de los criados, cuyo número sería notable, pues una morada de estas características así lo precisaba, aunque solo tenemos constancia de los que tuvieron un mayor contacto con el matrimonio: el mayordomo, Juan Bautista Ruxero; la doncella, Vicenta de Cora y Quirós; las criadas, Teresa Goñi y Catalina de la Peña, y el paje, Manuel Carvallo Valdés ${ }^{37}$.

El esplendor y magnificencia que desplegó en los dos inmuebles era similar a las grandes casas señoriales de la época, cuyo desembolso realizado fue de 770.000 reales de vellón. Otra de las cuestiones que lo avalan

36. AHPNM, P. ${ }^{\circ} 11447$, fols. 26-26v, 50-50v, 75-76v y 372-372r.

37. Algunas estancias de la vivienda se detallan en el inventario post-mortem de Juan Bautista Cassani. Biblioteca de la Real Academia de la Historia (BRAH), sig. 9/7234. 
son la importancia de los inquilinos que vivieron en ellas: el embajador del emperador, el conde Wenzel Ferdinand Popel de Lobkowicz, quien aseguró que de todas las casas que había visto en Madrid ninguna le había agradado tanto como esta, y la marquesa de Torrecuso, entre otros ${ }^{38}$.

Antes de finalizar las obras del hogar familiar Francisca Antonia tuvo a otra hija, María Teresa Blasa. Vino al mundo el 3 de febrero de 1668 y sería bautizada unos días más tarde. Su padrino fue su tío Marcos Cassani, que había venido a España para asistir a su hermano en la compañía. Al año siguiente nació Juan Bautista Manuel, quien sería apadrinado por el hermano Miguel, carmelita descalzo del convento de la Madre de Dios ${ }^{39}$. Dos semanas antes de que se produjera el alumbramiento de este hijo su padre compró para el deleite de la familia una gran finca a las afueras de Madrid, conocida con los nombres de Casa-Huerta o Casa-Puerta. La propiedad, de forma cuadrangular, tenía una extensión de más de 5 hectáreas y estaba completamente vallada de tapial. Sus anteriores dueños habían dado un uso agrícola a la hacienda, sin embargo, Juan Bautista Cassani dispuso también el espacio para residencia campestre, para lo cual trazó en el terreno unos caminos de tierra en forma de cruz griega que dividían el espacio en cuatro partes iguales. Las dos de la derecha, según se accedía, fueron dedicadas para campos de labor y huerta, la de la izquierda del fondo de la entrada, sería destinada para la arboleda de frutales, mientras que en la otra mandó construir un palacio con un jardín adornado con esculturas y fuentes de mármol al estilo de las villas romanas. Si en la casa de la calle del Lobo realizó un gran dispendio en esta residencia lo superó con creces. El verdadero alarde de ostentación lo plasmó en el citado palacio, cuyas paredes y techos fueron decorados por Dionisio Mantuano y Andrés Smith. En el oratorio los frescos tuvieron una temática de carácter religioso, mientras que en el salón principal y dos salas anejas las pinturas serían mitológicas y profanas. El resto de la vivienda fue adornada con cuadros de diferentes tamaños y estilos, así como con ricos muebles. Las obras concluyeron en 1674, según consta por la firma y fecha que Mantuano estampó bajo una de ellas ${ }^{40}$.

38. BRAH, sig. 9/3625. Carta escrita al coronel Beroldinghen el 12 de septiembre de 1690 . AHN, Jesuitas, Libro 248. Sobre el despliegue suntuario véase I. LuZÓN URUEÑa (2004).

39. APSSM, Libro de Bautismo n. ${ }^{\circ} 15$ p. 509, Libro de Bautismo 16, años 1668-1673, fol. 108.

40. AHPNM, P. ${ }^{\circ}$ 9820, fols. 568-570r; P. ${ }^{\circ}$ 11447, fols. 400-401r; P. ${ }^{\circ} 13704$, fols. 25-91. V. R. de Mesoneros Romanos (1903), 364-372. M. a I. Gea (2002), 561 y (2008), 63. I. Calvo y Sánchez (1924). J. del Corral (2004) y M. Gómez Oreña (2018b). 
Cuando los trabajos estaban en pleno apogeo sobre la familia se ciñó una grave tragedia. La viruela, una de tantas epidemias que afectaba a la sociedad de la época, penetró en la casa y se llevó por delante en el intervalo de 45 días a sus tres vástagos. Pese a que algunos autores señalan que el encariñamiento de los padres con sus hijos pequeños no era muy fuerte en este tiempo, el dolor de Juan Bautista Cassani y Francisca Antonia fue desgarrador, máxime porque quedaron sin ninguno con quien consolarse. Tal fue el sufrimiento padecido por la madre, según relata su marido en una carta, que incluso temió también perderla a ella ${ }^{41}$. Sin embargo, poco tiempo después, el 26 de marzo de 1673, dio a luz al pequeño José Félix Joaquín Domingo, al que bautizaron trece días más tarde, para el que elegirían como padres espirituales a dos religiosos ilustres, el nuncio cardenal Galeazzo Marescotti y el provincial de los capuchinos fray Francisco de Yecla ${ }^{42}$.

Este retoño fue un gran lenitivo para Francisca Antonia, con el que siempre se sintió muy unida. Igualmente su padre estaba muy encariñado con él, llevándolo consigo en muchos momentos. En cierta ocasión, un día que paseaban con el coche por la calle de Toledo, José Félix sacó la cabeza fuera de la ventanilla y contempló la iglesia de los jesuitas con gran curiosidad. A partir de entonces insistía constantemente a su progenitor para que lo llevara allí. La ocasión que eligió para que viera la magnificencia del templo fue con motivo de la celebración en ella de la imposición de un hábito a un caballero de una orden militar. Estando en este templo el pequeño, que solo tenía siete años de edad, visitó la capilla de la Virgen del Buen Consejo, de la que quedaría subyugado, convirtiéndose a partir de entonces en su luz y guía para toda su vida ${ }^{43}$.

El 29 de octubre de 1680 nacería otro hijo de la pareja, Juan Francisco Felipe Nicolás Antonio Narciso, quien sería bautizado el 5 de noviembre de ese año, siendo sus padrinos el nuncio Savo Millini y el fraile capuchino Francisco José. Aunque tampoco pasaría de la niñez, falleciendo con corta edad. El apoyo que siempre tuvo Francisca Antonia de su hermana Sebastiana en estos momentos de sufrimiento sería más valioso. Sin embargo, al poco tiempo pasaría esta última por un trance semejante, cuando su única

41. BRAH, signatura 9/3625, fols 103v-105r. Carta remitida al coronel Carlos Conrado de Beroldinghen en marzo de 1690.

42. APSSM, Libro de Bautismo, n. ${ }^{\circ} 16$.

43. G. Bousemart (1750). Este jesuita, que fue rector del Colegio Imperial, en una carta escrita a los padres superiores de Toledo alabando la virtuosa vida de José Cassani tras su fallecimiento en 1750 , señala algunas cuestiones sobre su infancia que concuerdan con las expuestas en la correspondencia epistolar de su progenitor. 
hija falleció a los dieciocho años de edad. Pese a que en aquella época se escribieron muchos tratados religiosos sobre la preparación y aceptación de la muerte, todos señalaban que era inevitable sentir dolor, aunque una buena cristiana debía llorar con mesura ${ }^{44}$. A partir de ese momento la vida de ambas se centraría en José Félix, cuyas grandes dotes para el estudio animarían a sus padres a proporcionarle un ayo y un maestro que le iniciase en la lectura y la escritura, enviándolo más adelante para continuar su aprendizaje al Colegio Imperial de la Compañía de Jesús. A los trece años despuntaba en gramática, retórica y poesía, pero cuanto más progresaba en sus conocimientos más fervor iba creciendo en su corazón. Tanto es así, que guiado por el ejemplo del beato Luis Gonzaga, cuya vida leyó durante dos años consecutivos, visitaba diariamente la capilla del Buen Consejo y, como él, solicitaba la exhortación de la Virgen para que le orientara en la lucha interior que sufría por seguir el camino religioso, contrapuesto al deber como hijo único de seguir la estirpe familiar.

El 15 de febrero de 1685, cuando José Félix estaba debatiéndose en estos lances, nació el pequeño y último descendiente de la familia, Nicolás Antonio Francisco Javier, para el que eligieron los mismos padrinos de bautismo que al anterior ${ }^{45}$. Con él se liberaba en parte el inconveniente de continuidad de la estirpe, aun así, dudaba que sus padres le dieran el pertinente permiso, quienes desconocían por completo sus anhelos. No obstante, su decisión era tan firme que se planteó entrar en secreto si no le autorizaban a hacerlo, lo cual no fue necesario, ya que cuando conocieron su determinación accedieron a sus deseos, principalmente porque el pequeño de la casa parecía rebosar de salud. Si bien, pusieron como condición visitarlo siempre que quisieran, aunque para Francisca Antonia fueron más reconfortantes los encuentros con José Félix cuando este regresaba al hogar con alguno de los padres de la compañía. Estos acontecimientos se daban con cierta frecuencia, dado que Juan Bautista Cassani mantenía una estrecha relación con los jesuitas, y estos, como agradecimiento, se hacían acompañar de su vástago. La primera vez que acudió a la vivienda para su madre supuso un inmenso júbilo, deshaciéndose en atenciones para con su hijo y sus doce acompañantes, a los que agasajó con chocolate y dulces. Las atenciones se harían extensibles a toda la compañía, ofreciéndoles su

44. AHPNM, P. ${ }^{\circ} 11453$, fols. 1053-1054r y 1074-1074v. Sobre el dolor por la pérdida de los seres queridos véase J. Caro Baroja (1978), P. Ariés (1984) y F. Martínez GiL (1993).

45. APSSM, Libro de Bautismo, n. ${ }^{\circ}$ 18, fol. 509. 
finca para celebrar las jornadas campestres que realizaban a lo largo del año, especialmente en primavera ${ }^{46}$.

Al igual que en ocasiones anteriores, estos felices acontecimientos se verían truncados por el deceso del pequeño Nicolás Antonio. Pese a que se criaba sano y robusto tras haber pasado el sarampión, un simple catarro acabó con él pocos días antes de cumplir los tres años. Este momento tan trágico lo tuvo que afrontar Francisca Antonia sin el consuelo de su marido, quien se hallaba postrado en la cama con uno de los intensos ataques de gota que padecía. Aunque por unas pocas horas pudo ser reconfortada por el único hijo que le quedaba. Este fallecimiento trastocaba los planes que habían dispuesto los progenitores, pues otra vez la casa quedó vacía sin sucesión. No es de extrañar que el padre lamentara que Dios se hubiera llevado a todos sus herederos, seis al cielo y uno al convento, desconsuelo que le entristecía aún más al pensar en su mujer, por la que sentía un gran cariño y admiración ${ }^{47}$.

Francisca Antonia acudía muy afligida todos los días al noviciado para que su hijo abandonara el estado religioso y volviese con ella a casa. Las súplicas ni las lágrimas lograron disuadirlo, todo lo contrario, el joven logró convencerla arguyendo:

La muerte de mi hermano, que usted me alega como motivo para llevarme a su casa, es para mí un argumento muy claro de que Dios me quiere en la suya. Las circunstancias en que vino al mundo, cuando ustedes me rehusaban la licencia, quién no ve que vino solo para facilitarla y las mismas circunstancias en que se ha ido al cielo claramente lo confirman, pues prueban que no tenía más destino cuando concluido este asunto vemos que Dios se lo lleva al cielo. Que usted lo sienta no es extraño, pero usted debe estar consolada y yo muy agradecido, pues veo que a Dios el asegurarme a mí le ha constado hacer un ángel. [...] En dejarme seguir el rumbo empezado no me pierde usted, abandonarle yo fuera perderme. Y, por fin, señora, si usted me quiere tanto como asegura, yo creo sirva este cariño de rogar a Dios que me haga buen jesuita, porque en todo caso jesuita tengo de $\operatorname{ser}^{48}$.

46. BRAH, signatura 9/3642. Cartas remitidas a su hermana Ana Teresa el 7 de febrero de 1687 y 4 de abril de 1688, y al provincial de Toledo Francisco Morejón el 17 de abril de 1687.

47. BRAH, Signatura 9/3642. Carta remitida a su hermana Ana Teresa el 6 de febrero de 1688

48. G. Bousemart (1750). 
Finalmente, la madre aceptó su voluntad por el gran cariño que le profesaba, aunque también fue motivado porque la quiebra económica que atravesaba en ese momento el matrimonio hacía inviable un futuro prometedor para el joven.

\section{LOS PROBLEMAS ECONÓMICOS Y FINANCIEROS}

La compañía mercantil y financiera de Juan Bautista Cassani manejaba un importante volumen de negocio, por lo que sus ingresos fueron de una gran magnitud. Sin embargo, determinadas circunstancias le condujeron finalmente a la bancarrota. Posiblemente la más trascendente estaba ligada al acceso a la embajada, que le llevó a realizar unos gastos desmesurados, no solo en el boato desplegado en su vida cotidiana, sino también en la construcción de sus respectivas viviendas. A la par que ejecutaba estas obras le sobrevinieron varios contratiempos en las transacciones mercantiles que le impidieron percibir importantes adeudos, que sumados a la reforma monetaria de 1680 afectaron considerablemente a su economía. Situación que se agravaría cuando la Cámara Apostólica le exigió el ajuste de cuentas de los últimos diez años, las cuales no pudo cubrir en ese momento, por lo que se le retiró la tesorería y se le embargaron algunas joyas y la finca ${ }^{49}$. Esto sería el detonante que le llevó al concurso de acreedores.

En cuanto a los Cantones Católicos también quisieron despedir a Juan Bautista Cassani de su cargo de embajador. No obstante, su elección como tal se sustentó en los grandes préstamos que les entregó para el mantenimiento de los regimientos suizos que sirvieron en las tropas españolas ${ }^{50}$. En 1680 todavía no los habían cubierto, por lo que decidieron entregarle por dos vidas las rentas de un juro de la media anata de mercedes que la Corona les entregó como pago por sus asistencias. Dicho juro no se podía enajenar porque la administración solo lo abonaría al diplomático de ese territorio que estuviera acreditado en Madrid. Por tanto, si le expulsaban debían primero saldar las cuentas, pero como no lo pudieron hacer en ese momento, optaron por su continuidad en el puesto. Esto le supuso a Juan Bautista Cassani una serie de privilegios. El primero, que debido a su estatus diplomático se le concedió un juez conservador para que su casa no fuera atropellada por los acreedores. El segundo, seguir disfrutando de un cierto lujo después de la bancarrota, pues como tal tenía derecho al sueldo,

49. AHPNM, P. ${ }^{\circ} 11455$, fols. 78-80r.

50. Sobre los regimientos suizos en las tropas españolas véase M. GómEZ Oreña (2019). 
las franquicias y la inmunidad diplomática que facilitaba la consecución de algunos negocios. El tercero, que pudo conservar su casa de la calle del Lobo, aunque la finca, pese a que le fue devuelta por la Cámara Apostólica cuando saldó sus deudas con ella, finalmente sería vendida judicialmente a un compatriota y amigo suyo, el marqués de los Balbases, Pablo Spínola Doria, que dejó de serlo por haberle obligado como acreedor a transferírsela.

En el plano económico la vida de Francisca Antonia tras la bancarrota no cambió sustancialmente, pues a las prerrogativas señaladas anteriormente se sumaba la disponibilidad de las rentas del mayorazgo, que por ser un bien privativo no podían emplearse para pagar a los acreedores. Testimonio de que la familia siguió viviendo con ostentación lo podemos constatar en el inventario post-mortem, cuyo volumen fue de una gran magnitud en mobiliario, obras de arte, objetos suntuarios, joyas, coches, etc., lo que reportó grandes beneficios al heredero, el Colegio Jesuita de Alcalá de Henares.

A pesar de seguir viviendo acomodadamente, Francisca Antonia se involucraría en la difícil situación económica por la que estaba atravesando la compañía de su esposo. Los adeudos que no le fueron satisfechos le impedían hacer frente a sus propios descubiertos. Uno de casi 500.000 reales de vellón correspondía al duque de Alba, quien, aprovechando las difíciles circunstancias por las que estaba atravesando Juan Bautista Cassani, eludía el pago. Este último, planearía diferentes estrategias para cobrarlos, pero como ninguna funcionaba decidió recurrir a su esposa, quien en connivencia con sus amigas debía forzar a la duquesa de Alba para que influyera en su marido. Esta se comprometió a no dejar el asunto de sus manos hasta la completa liquidación de las cuentas, no obstante, no fue saldada ${ }^{51}$.

No todas las diligencias que realizó Francisca Antonia para obtener liquidez fueron orquestadas por su marido. Hecho constatado fue la transacción de una joya de gran valor engarzada con 31 diamantes y un copete de oro con boquillas de plata. Para evitar ser descubierta la venta la realizó a través de una amiga, María de Herrera, quien se ocupó de despacharla en su nombre. Sin embargo, cuando Juan Bautista Cassani lo supo solicitó judicialmente, alegando que su mujer ejecutó la venta sin su permiso, se declarase nula la operación y le restituyesen dicha joya, pues había sido tasada por un valor muy inferior al real. Pese a no conocer la sentencia final, cabe suponer que esta cuestión se solventaría favorablemente a tenor

51. BRAH, signatura 9/3642. Cartas de Juan Bautista Cassani remitidas a Francisco Barlettani el 20 de agosto de 1687, y a Juan de Palazol el 17 de abril de 1687. 
del sometimiento jurídico que tenían las mujeres respecto al varón ${ }^{52}$.

Estas dos actuaciones de Francisca Antonia en cuestiones relacionadas con los negocios de su marido, junto a su papel como anfitriona en los banquetes ofrecidos a las amistades y a las destacadas personalidades con las que trataba, nos ponen en valor el papel desempeñado por las mujeres en la consecución de asuntos propios de hombres, punto que se viene analizando ya en numerosas investigaciones ${ }^{53}$.

\section{LAS ÚLTIMAS VOLUNTADES}

La muerte de sus retoños, la bancarrota de su marido y el acceso al noviciado de su único descendiente hicieron mella en el ánimo y en el cuerpo de Francisca Antonia. Para paliar la soledad del hogar visitaba diariamente la capilla de la Virgen del Buen Consejo del Colegio Imperial, donde se consolaba viendo a su hijo, aunque solo fuera por unos minutos. Sin embargo, cuando este se trasladó a Villarejo de Fuentes y a Alcalá de Henares para perfeccionar sus estudios continuó yendo allí para reunirse con una congregación de señoras que oraban juntas por el alma de las cofrades fallecidas ${ }^{54}$. Este oratorio se constituiría en bálsamo para su espíritu, por lo que decidió que tras su muerte depositaran allí sus restos.

Unos meses antes de su fallecimiento, viendo que sus fuerzas iban mermándose poco a poco, decidió poner en orden todas las cuestiones materiales y espirituales. En cuanto a las primeras, su prioridad fue el bienestar de su hijo, que por ser religioso no podía heredar el mayorazgo, por lo que concertó con su hermana Sebastiana, siguiente en la sucesión, detraer 2.200 reales anuales de las rentas del vínculo y asignárselas al religioso para que cubriera sus pequeñas necesidades ${ }^{55}$. La gravedad de su enfermedad le impediría realizar su testamento, por lo que estando postrada en la cama firmó un poder notarial a su marido para que en su nombre cumpliera sus últimas voluntades. En los momentos finales de su vida estuvo asistida por su hijo, su hermana, sus más íntimas amistades y su esposo, quien siempre demostró un gran cariño por ella. El 21 de abril de 1687, después de haber recibido los Santos Sacramentos, falleció Francisca Antonia cuando le faltaban unos días para cumplir cuarenta y nueve años.

52. AHPNM, P. ${ }^{\circ} 13542$, fols. 193-193v y 219-219v.

53. Véase P. Pezzi Cristóbal (2012) y M. V. López Cordón (2015).

54. AHN, Clero, Jesuitas, Libros 76 j, 88 j.

55. AHPNM, P. ${ }^{\circ} 13542$, fols. $84-85$ r. 
La religiosidad estuvo muy presente en la sociedad de la época que nos ocupa, ya que la muerte visitará con frecuencia a familiares, amigos y vecinos, por lo que prepararse para el tránsito hacia la otra vida era una cuestión de vital importancia, especialmente para Francisca Antonia y su cónyuge ${ }^{56}$. Su reclusión en el convento y el estar rodeada de familiares religiosos -tías, hermanos e hijo- acrecentarían su devoción, la cual queda patente en una multitud de objetos que poseía, entre otros, relicarios, agnus, imágenes religiosas y libros piadosos - guías espirituales, hagiografías y novenarios-, que en el caso de haber aprendido a leer, contribuirían a prepararse para este trance, que lo dispuso con una estricta rectitud. Contrariamente a la suntuosidad desplegada en los sepelios de la alta sociedad, Francisca Antonia estableció para el suyo que fuera de secreto, es decir, sin acompañamiento y de noche, el cual solía realizarse entre las once y las dos de la mañana. De esta manera acreditaba su humildad ante Dios. Sin embargo, para la salvación de su alma fue mucho más generosa, pues estableció que se celebrasen 4.000 misas, a razón de 3 reales cada una, salvo la cuarta parte de ellas, que era de obligado cumplimiento oficiarlas en la propia parroquia, la de San Sebastián, el resto se celebrarían donde establecieran sus testamentarios, que fueron, además de su marido y su hijo, Domingo de Damisa González y el padre Nicolás González, que probablemente fuera su confesor, pues estuvo presente en sus últimos momentos. También ordenó que se entregaran a las mandas forzosas y santos lugares de Jerusalén 8 reales $^{57}$.

En cuanto a los legados materiales dejó establecido que a la imagen de su adorada Virgen del Buen Consejo se entregara una reliquia grande de la Santa Cruz que estaba guarnecida de diamantes y rubíes. A la Virgen del Rosario de la Iglesia de la aldea de Casarrubuelos, de la que se hizo devota la única vez que visitó el lugar, donó una lazada de oro con diamantes de Bohemia y un vestido de brocado de oro y encajes de plata, para que con él le hiciesen un traje y un manto. Para el convento de capuchinos de San Antonio, por la gran devoción que tuvo por esa iglesia y por los propios padres, quiso que les dieran una limosna de 1.100 reales de vellón. A los seres más queridos, su esposo e hijo, les señaló, al primero como su heredero universal, y al segundo la citada renta anual del vínculo que disfrutaría para el resto de sus días. Dicha cantidad, cuando él falleciera, se aplicaría a la fundación de una capellanía perpetua de misa rezada todos los domingos del año por el alma del religioso, de su marido y de ella misma

56. M. Gómez Oreña (2015).

57. Sobre el ritual funerario véase M. ${ }^{a}$ J. García Gascón (1989) y F. Martínez Gil (1993). 
en la Iglesia de san Pablo y san Pedro del Hospital de los Italianos. Para su inseparable y amada hermana mandó un par de pendientes de perlas y un vestido negro de tercianela de Nápoles.

Dentro de los adeudos más íntimos tuvo presente a María y Jerónima, las hijas de su estimada amiga Teresa González, esposa de Domingo de Damisa. A la primera donó una reliquia de san Isidro guarnecida de finas piedras, a la segunda un retrato pequeño de la Virgen de Belén de igual talla. A Antonia Justiniano, por la que sentía un gran cariño, una Virgen con el Niño en brazos pintada en raso, con un cristal delante y una cornisa dorada y negra. Para la madre carmelita descalza del convento de Santa Ana, a la que estaba muy unida, una imagen de bulto de santa Teresa. De la misma forma tuvo en cuenta Francisca Antonia al personal que sirvió en la vivienda o los negocios. Para aquellos con los que tuvo un trato más íntimo les asignó importantes cantidades de dinero, como a la doncella Vicenta de Cora y Quirós, que por haberse criado en su casa designó que por el tiempo que estuviere en ella, además de la comida, se le asignasen 30 reales de salario al mes hasta cumplidos los veinticuatro años. No obstante, si por cualquier motivo se fuera de la vivienda, 2,5 reales cada día, además cuando tomara estado se le entregarían 5.500 reales de vellón. A Catalina Atego, para el mismo fin, mandó 2.200 reales de vellón. Esta misma cantidad señaló para María y Antonia, hijas del secretario de su marido, Diego Puche. Al resto de las criadas legó un vestido que ella eligió previamente ${ }^{58}$.

Las disposiciones que ordenó Francisca Antonia fueron cumplidas por su marido y su hijo. Este último, en 1725, instituiría en honor de su madre una memoria de misas en la capilla del fundador del colegio de la Compañía de Jesús de Loyola, que se sustentaría con un censo de 20000 reales de principal que había impuesto el colegio de Alcalá de Henares a favor del propio José Félix Cassani ${ }^{59}$. Esta deferencia le fue asignada en reconocimiento al legado paterno para esa institución. También el general de la Compañía, Miguel Ángel Tamburini, le daría las gracias por ello a través de una carta, en la que además le informó que había ordenado realizar sufragios en todas las instituciones jesuitas en memoria de su padre y de él mismo, encomendándoselo con mayor encarecimiento al colegio de Lucerna, por haberle dejado un legado de 4.200 reales de vellón anuales por el tiempo que durase su hacienda ${ }^{60}$.

58. AHPNM, P. ${ }^{\circ} 13452$, fols. 193-193v.

59. AHN, Jesuitas, leg. 611, expediente n. ${ }^{\circ} 4$.

60. AHN, Jesuitas, leg. 611, expediente n. ${ }^{\circ}$ 4. Cartas fechadas en Roma el 29 de agosto y el 5 de diciembre de 1719. 


\section{CONCLUSIONES}

El marcado sentimiento paternalista que ejercía el hombre sobre la mujer en la época que nos ocupa ha quedado reflejado a lo largo de esta investigación a través de la vida de Francisca Antonia Fernández de Merodio, una mujer de la alta sociedad. De hecho, pese a que durante su minoría de edad su padre encomendó el cuidado de sus hijas a sus hermanas religiosas, estas no tuvieron su tutela, como lo demuestra que tras el fallecimiento paterno se buscara un tutor para ella, Antonio Fernández de Morales, quien detentó este cargo hasta que fue sustituido por Simón, el hermano de la susodicha. Este pasaría el testigo al marido, quien lo ejercería hasta el final de su vida. Es más, ni siquiera tuvo potestad sobre su hijo para que abandonara el noviciado cuando su casa quedó sin descendencia.

Otra cuestión que hemos subrayado es el sentido religioso de nuestra protagonista, que era más acentuado que el imperante en los siglos de la modernidad. Varias serían las razones que la orientaron en esta dirección. Entre ellas, haber nacido en un hogar en el que existía una predisposición hacia la vida espiritual dentro del seno de la Iglesia, pues no solo dos de sus hermanos tomaron este camino, sino que también lo haría su padre, lo que motivó el ingreso de sus hijas en un convento para criarse en él. Por otra parte, al ser su marido tesorero de la Cámara Apostólica, mantuvo contacto directo con las altas instancias religiosas, influyéndola notablemente, de hecho, varios nuncios apostólicos fueron padrinos de sus hijos, al igual que lo fueron miembros de diferentes órdenes religiosas. De entre estas últimas, con la que tuvo un vínculo mayor sería con los jesuitas, especialmente desde la entrada de su hijo en la Compañía de Jesús.

Por otro lado, la muerte y las desgracias, que no hacían distinción de clase por muy elevada que fuera esta, han quedado también patentes en este trabajo. La espiritualidad y devoción de Francisca Antonia no menguarían tras los episodios frecuentes de enfermedad y muerte que asolaron su familia, cuyo hecho más dramático sería la pérdida de tres de sus hijos en tan solo 45 días tras una epidemia de viruelas, quedando su casa sin descendencia. Este acontecimiento fue extremadamente duro para ella, al igual que lo sería el fallecimiento de los otros tres pequeños. Si bien, el intervalo del deceso entre unos y otros se espació en el tiempo, dos de ellos después del nacimiento de José Félix, por lo que este último mitigaría en parte el dolor al poder consolarse con él. Pero tras su ingreso en el noviciado, la Capilla de la Virgen del Buen Consejo se constituiría como un lenitivo.

Queda constancia también de la participación económica testimonial de la mujer en la sociedad matrimonial, donde el papel de esta se resumía 
en ser anfitriona doméstica con el fin de facilitar los intereses mercantiles y financieros del matrimonio. El entorno de ostentación y lujo que disfrutó Francisca Antonia sería determinante para este fin, dada la condición de banquero y embajador de su marido. Esto le permitió disfrutar de unas majestuosas viviendas, cuya riqueza decorativa en mobiliario y objetos suntuarios le permitía agasajar a su círculo más íntimo de amistades y para aquellas que no lo eran tanto, pero por necesidades concernientes a los negocios de su marido lo precisaban, especialmente cuando cayó en bancarrota.

\section{BIBLIOGRAFÍA}

Aparisi Laporta, Luis Miguel (2001), "Toponimia Madrileña. Proceso evolutivo", Anales del Instituto de Estudios Madrileños, XLI, pp. 39-68.

ArIÉs, Philippe (1984), El hombre ante la muerte, Taurus, Madrid.

Barbeito CARneiro, María Isabel (1990), Mujeres del siglo XVII entre Europa y Madrid, Instituto de Estudios Madrileños, Madrid.

Bousemart, Gabriel (1750), Carta del padre Gabriel Bousemart, rector del Colegio Imperial de Madrid, para los padres superiores de la provincia de Toledo, sobre la religión, vida y virtudes del padre Joseph Casani, difunto el día 12 de noviembre de 1750, Biblioteca Virtual Miguel de Cervantes.

Calvo y SÁnchez, Ignacio (1924), "La Finca madrileña "Casa-Puerta»", Revista de la Biblioteca, Archivo y Museo del Ayuntamiento de Madrid, 3, pp. 269-285.

Camacho Martínez, Rosario (1980), "La Iglesia del Hospital de San Juan de Dios en Antequera", Boletín de Arte, 1, pp. 63-74.

Caro Baroja, Julio (1978), Las formas complejas de la vida religiosa. Religión, sociedad y carácter en la España de los siglos XVI y XVII, Akal, Madrid.

Carretero Zamora, Juan Manuel (2013), "La Colectoría de España en el siglo XVI: los mecanismos de transferencia monetaria entre España y Roma (cambios y créditos)", Hispania. Revista Española de Historia, LXXIII, 243, pp. 79-103.

Corral, José del (2004), Casas madrileñas desaparecidas. Misterios, amores e intrigas, Sílex, Madrid.

GARCía GASCÓn, M. ${ }^{a}$ José (1989), "El ritual funerario a finales de la Edad Moderna: una manifestación de la religiosidad popular", en L. C. Álvarez Santaló,

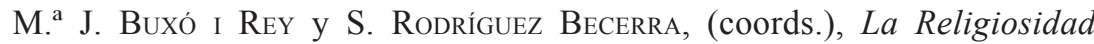
Popular, vol. II, Anthropos, Barcelona, pp. 328-343.

García Guerra, Elena M. (1990), "La mujer en la Historiografía modernista española", Hispania, revista española de Historia, L, 176, pp. 1105-1122.

GeA, María Isabel (2002), "Finca Casa-Puerta", Madrid Histórico, 15.

- (2008), "Posesión de la Casa-Puerta", en Diccionario enciclopédico de Madrid, Ediciones La Librería, Madrid. 
Gómez OreñA, Mercedes (2015), "La espiritualidad de un hombre de negocios genovés asentado en el Madrid del siglo XVII. Juan Bautista Cassani Vivaldo", Revista Destiempos, 44, pp. 47-76.

- (2017), "Juan Bautista Cassani Vivaldo. Un hombre de negocios genovés representante diplomático de los Cantones Esguízaros en el Madrid de Carlos II", Cuadernos de Historia Moderna, 42, 1, pp. 87-106.

- (2018a), Juan Bautista Cassani. Un banquero genovés en la España del siglo XVII, Editorial Académica Española.

- (2018b), "Nuevas aportaciones a la historia de la Casa-Puerta. Una villa de estilo italiano en el Madrid del siglo XVII", Revista Destiempos, 61, pp. 13-46.

- (2019), "Los esguízaros en los conflictos bélicos de la corona española. Una aproximación a la contratación y licenciamiento durante la embajada de Juan Bautista Cassani (1667-1704)", Revista de Historia Militar, 126, pp. 149-174.

Hernández Sandoica, Elena (2004), "La historia de las mujeres e historia de las relaciones de género", en M. ${ }^{\mathrm{a}}$ I. VAL VALDivieso (coord.), La historia de las mujeres: una revisión historiográfica, Universidad, Valladolid, pp. 31-32.

JimÉnez LóPez de Eguileta, Javier (2018), “Micer Bonavía de Vivaldo, alcaide de El Puerto de Santa María, y los orígenes del latifundismo en la baja Andalucía (siglos XIII y XIV)", Revista de Historia de El Puerto, 60, pp. 133-147.

LóPEZ-CORDÓn, M. ${ }^{a}$ Victoria (1999), "Mujer e historiografía: del androcentrismo a las relaciones de género", en A. Reig, J. L. de la Granja Sainz y R. F. J. Miralles Palencia (coords.), Tuñón de Lara y la historiografía española, Siglo XXI, Madrid, pp. 257-278.

- (2015), "Los estudios históricos sobre las mujeres en la Edad Moderna: estado de la cuestión", Revista de Historiografía, 22, pp. 147-181.

López Millán, Miguel Ángel (2014), “Linaje y matrimonio en la España Moderna. Las capitulaciones matrimoniales entre Gaspar Téllez-Girón y Feliche Gómez de Sandoval (1642)", Revista Historia Autónoma, 4, pp. 83-96.

Lozón Urueña, Ignacio (2004), Madrid. Capital y Corte. Usos, costumbres y mentalidades en el siglo XVII, Madrid en el Tiempo, Madrid.

Martínez Gil, Fernando (1993), Muerte y Sociedad en la España de los Austrias, Siglo XXI, Madrid.

Martínez de Oporto, Pablo (2019), “Una cuestión histórica de género. La desigualdad educativa y el aprendizaje de la mujer en España”, Trabajo Social Global- Global Social Work, 9, 16, pp. 202-224.

Mesoneros Romanos, Ramón de (1903), Trabajos no coleccionados. Reformas de Madrid y de su administración. Amena literatura, tomo I, Hijos de M. G. Hernández, Madrid.

Morant, Isabel (dir.) (2005), Historia de las mujeres en España y América Latina. El mundo moderno, vol. 2, Cátedra, Madrid. 
Oliván SAntaliestra, Laura (2019), “Cartas para Johanna: una aproximación a la red epistolar de la condesa de Harrach (1661-1700)", en B. J. GArcía García, K. Keller y A. Sommer-Mathis (eds.), De puño y letra: cartas personales en las redes dinásticas de la Casa de Austria, IberoamericanaVervuet, Madrid-Frankfurt am Main, pp. 345-376.

Pezzi Cristóbal, Pilar (2012), "Mujeres en el contrabando. La participación femenina en un negocio de hombres", Baetica. Estudios de Arte, Geografía e Historia, 34, pp. 991-402.

Rivarola y Pineda, Juan Félix Francisco de (1729), Descripcion historica chronologica y genealogica, civil, política, y militar de la Sereníssima República de Génova, por Diego Martín Abad, Madrid.

Ruiz Sastre, María (2018), El abandono de la palabra. Promesas incumplidas y ruptura de noviazgo en el arzobispado sevillano durante el siglo XVII, Fundación Española de Historia Moderna, Madrid.

SAnZ Ayán, Carmen (1988), Los banqueros de Carlos II, Universidad, Valladolid.

- (2019), "Negocio, dinero y mujer. Empresarias en la primera época moderna (ss. XVI y XVII)", Boletín de la Real Academia de la Historia, CCXVI, II, pp. 149-169.

Segura Graíño, Cristina (ed.) (1997), La historia de las mujeres en el nuevo paradigma de la Historia, Asociación Cultural Al-Mudayna, Madrid.

Tenorio Gómez, Pilar (2001), Realidad social y situación femenina en el Madrid del siglo XVII, Universidad Complutense, Madrid.

Toquica Clavijo, María Constanza (2001), "Religiosidad femenina y la vida cotidiana del convento de santa Clara de Santafé, siglos XVII Y XVIII. Una mirada detrás del velo de Johanna de San Esteban", Revista colombiana de Antropología, 37, pp. 152-186.

UrzÁiz Tortajada, Héctor (2002), "Del entremesista-bufón al "hijo del Boticario": perfiles del dramaturgo del Siglo de Oro", Revista de Investigación Teatral, 9, pp. 9-26.

VIGIL, Mariló (1986), La vida de las mujeres en los siglos XVI y XVII, Siglo XXI, Madrid. 